\title{
Comparison of endotracheal tube cuff pressures inflated with saline or air in gynecological laparoscopic surgery
}

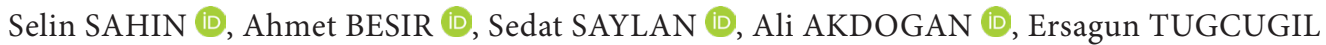

Department of Anestesiology and Reanimation, School of Medicine, Karadeniz Technical University, Trabzon, Turkey.

Corresponding Author: Ahmet BESIR

E-mail: ahmetbesir61@gmail.com

Submitted: 25.11.2020 Accepted: 13.02.2021

\begin{abstract}
Objective: We compared the air or saline insufflated endotracheal tube (ETT) cuff pressures and their effects on postoperative respiratory complications in gynecological laparoscopic surgeries in the Trendelenburg position (TP).

Patients and Methods: This prospective study was carried out on a total of 60 patients, whose ages ranged from 18 to 65 years and who were classified by the American Society of Anesthesiologists (ASA) as I-III. They were scheduled for gynecological laparoscopic surgery in TP. Patients included in the study were randomly divided into two groups as the saline (Group S, n=30) and air (Group A, $\mathrm{n}=30$ ) groups. ETT cuff pressures and peak airway pressures were recorded immediately after intubation and at 10-minute intervals during the intraoperative period.

Results: The cuff pressure and maximum cuff pressure values in the saline group were significantly lower than in the air group in the 50 -minute $(\mathrm{p}<0.05)$. The sore throat and analgesic consumption were significantly lower in Group $\mathrm{S}$ in postoperative 24 hours $(\mathrm{p}<0.001$, for all).

Conclusion: The intraoperative cuff pressures, postoperative sore throat, and analgesic consumption were lower in the salineinsufflated group than in the air-insufflated group in gynecological laparoscopic surgery in TP.

Keywords: Laparoscopic surgery, Trendelenburg position, Sore throat, Cuff pressure.
\end{abstract}

\section{INTRODUCTION}

Endotracheal intubation (EI) is the process of tube placement in the trachea to maintain the respiratory tract open and regulate breathing. The environmental pollution that may result from aspiration of gastric contents into the airway, gas leakage, and release of medical gases to the external environment is prevented by the cuffed endotracheal tubes (ETT) used during EI monitoring [1].

Close monitoring of the ETT cuff pressures insufflated immediately after EI and during the intraoperative period, with a cuff manometer is essential during general anesthesia. Although, cuff pressures are closely monitored after tracheal intubation, cuff pressures can also be affected by various factors such as patient position, temperature, and degree of neuromuscular blockade [2-4]. Besides, used medical gases such as oxygen, nitrous oxide, volatile inhalation agents can also have an effect on cuff pressures.

More severe complications such as transient hoarseness, sore throat, tracheal mucosal ulcer, nerve palsy, tracheal rupture, or fistula and subglottic stenosis can be observed due to the increase in high volume-low pressure ETT cuff pressures that are frequently used during general anesthesia [5-8]. Tracheal ulcers are more common in intubated intensive care patients after longterm intubation. Most complications occur due to high ETT cuff pressures, especially ischemia of the mucosa in the anterolateral surface of the trachea [9]. These complications can be prevented by keeping tracheal cuff pressures within the $20-30 \mathrm{~cm} \mathrm{H}_{2} \mathrm{O}$

How to cite this article: Sahin S, Besir A, Saylan S, Akdogan A, Tugcugil E. Comparison of endotracheal tube cuff pressures inflated with saline or air in gynecological laparoscopic surgery. Marmara Med J 2021; 34(2):140-146. doi: 10.5472/marumj.942649 
range, which is regarded as safe. These cuff pressure values are considered to be below the values that impair the perfusion of the tracheal mucosa and above the values preventing possible tracheal aspiration [10-14].

Laparoscopic surgery technique is frequently preferred to open surgery in recent years due to its less invasiveness, less post-operative pain, and providing faster recovery [15]. The endotracheal cuff pressure is known to increase in operations performed in the Trendelenburg position (TP) in the laparoscopic surgery technique [16].

As a result of the insufflation of the stomach with $\mathrm{CO}_{2}$ during the laparoscopy, intrathoracic pressure increases and lung compliance decreases in the TP. This causes an increase in cuff pressure and related complications [15]. Many drugs and methods have been used to prevent postoperative complications due to tracheal mucosa damage that occurs after the excessive swelling of cuff pressures [17-19].

The primary aim of the present study was to compare the ETT cuff pressures insufflated with air or saline during the laparoscopic gynecological operations performed in the TP and to assess sore throat complications in the postoperative period. The secondary aim is to investigate the correlation of postoperative period duration with surgical position, peak airway pressures and changes in cuff pressures.

\section{PATIENTS and METHODS}

Our study was conducted as a prospective clinical study in Anesthesiology and Reanimation Department between August 2017 and March 2018. The study protocol was approved by the Institutional Ethics Committee of Karadeniz Technical University, School of Medicine (approval number: 09.2013. 0262). All patients provided written informed consent.

Sixty-two patients who were scheduled to have laparoscopic gynecological surgery in the TP were included in the study. The patients were between 18-65 years old, and in the American Society of Anesthesiologists (ASA) I-III risk group. The expected operation time was 60-180 minutes. Two patients were excluded from the study, as one patient's cuff pressure was deformed which caused unreliable values, and one patient's operation time was less than 60 minutes.

Patients with neurological and psychiatric disorders, serious cardiovascular and respiratory diseases, an upper respiratory infection in the last ten days and had treatment,

a history of smoking, who was morbidly obese, who had a known allergy to anesthetic agents, alcohol or drug addiction, a history of bronchospasm, anticipation of difficult intubation, estimated duration of surgery below 60 minutes or more than 180 minutes, with a history of malignant hyperthermia, unexpected difficult intubation, who could not be intubated with first-time insertion success and whose cuff pressures were above $40 \mathrm{mmHg}$ during follow-up periods were excluded from the study. Besides, patients with tracheostomy and severely disordered pulmonary compliance including airway anomaly and chronic obstructive pulmonary disease were excluded from the study.
The patients in both groups were administered $0.015 \mathrm{mg} /$ $\mathrm{kg}$ midazolam as premedication 15 minutes before anesthesia induction in the operating room. Patients were given preoperative 30 -min infusion of $10 \mathrm{ml} / \mathrm{kg} / \mathrm{h} 0.9 \%$ sodium chloride. After patients were taken to the operating table, electrocardiography (ECG), heart rate (HR), non-invasive mean arterial pressure (MAP), peripheral oxygen saturation $\left(\mathrm{SpO}_{2}\right)$, end-tidal $\mathrm{CO}_{2}$ $\left(\mathrm{EtCO}_{2}\right)$, (Spacelabs Healthcare, Snoqualmie, WA, USA) and bispectral index (BIS) (Aspect Medical Systems, Norwood, MA, USA) were applied in standard monitoring.

Patients included in the study were divided into two groups after their ETT cuffs were randomly insufflated with saline (Group S, $\mathrm{n}=30$ ) or air (Group A, n=30) to a pressure of $25 \mathrm{~cm} \mathrm{H}_{2} \mathrm{O}$ with the help of a cuff pressure manometer (VBM, Medizintechnic $\mathrm{GmbH}$, Germany) after EI. Randomization was performed before group assignment using computer-assisted random numbers from www.randomization. Cuff pressure follow-ups were performed with a cuff pressure manometer.

After pre-oxygenation with $100 \%$ oxygen for three min., $1 \mu \mathrm{g} / \mathrm{kg}$ fentanyl, $1 \mathrm{mg} / \mathrm{kg}$ lidocaine, $2-3 \mathrm{mg} / \mathrm{kg}$ propofol, and $0.6 \mathrm{mg} / \mathrm{kg}$ rocuronium were administered for the induction of anesthesia. After sufficient time for muscle relaxation, EI was performed after the BIS values decreased below 60 (Macintosh blade 3 or 4). Before the EI procedure, cuff leakage control was done, and straight tubes with an inner diameter of 7 to $7.5 \mathrm{~mm}$ were used. Intubation was performed by anesthesiologists who had 3 to 4 years of experience. Following a successful EI, patients were ventilated with tidal volumes of $6-8 \mathrm{ml} / \mathrm{kg}$, frequencies of 10-12/ min. and 32-35 mmHg EtCO ${ }_{2} \mathrm{O}_{2 /}$ air (1:1) and 2-3\% sevoflurane gas mixture was used and $0.05-2 \mathrm{mcg} / \mathrm{kg} / \mathrm{min}$ remifentanil infusion was administered for the maintenance of anesthesia in both groups The required depth of anesthesia was adjusted to be between BIS 40-60. Sevoflurane concentration was titrated to a maximum of $3 \%$ with $1 \%$ increase in cases without tachycardia and hypertension, whose BIS values were above 60. Muscle relaxants, hypnotics, and analgesics were administered when necessary. Heart rates, oxygen saturation, mean arterial pressure (MAP), BIS values, cuff pressure values, highest cuff pressure values, $\mathrm{EtCO}_{2}$, inspired oxygen values, internal positive end expirium pressure (PEEP), and peak airway pressure values of all patients were recorded before induction, after intubation, in 10 - min intervals after induction and just before extubation. Besides, the highest values of airway and cuff pressures of the patients in the TP were also recorded.

At the end of the operation, when all patients had train-of-four (TOF) value above $25 \%$, the non-depolarizing muscle relaxant was antagonized with $0.04 \mathrm{mg} / \mathrm{kg}$ neostigmine $+0.01 \mathrm{mg} / \mathrm{kg}$ atropine. When they all had an adequate respiratory depth and rate and had stable cardiovascular findings, the patients were extubated after oropharyngeal secretions were removed. The patients were taken from the operating room to the postanesthesia care unit (PACU) when sufficient muscle strength (the ability to lift the head and move the extremities according to the commands) was observed, and airway stability was adequate. Patients with an Aldrete score of $\geq 9$ were sent to the service from PACU [21]. Besides, sore throat in both groups 
was evaluated in the postoperative period with the numeric rating scale (NRS) scoring system (NRS 0 was described as painlessness and NRS 10 was described as the worst pain ever experienced) when they were swallowing and not swallowing, and the patients with an NRS score of $>3$ were administered iv. $50 \mathrm{mg}$. tramadol in PACU and in wards. In the postoperative period, the NRS scores at the 2nd and 24th hours, and the amount of analgesic used during the first 24 hours were evaluated and recorded.

\section{Statistical Analysis}

The sample size was calculated based on the cuff pressure parameter. After setting the alpha error level at 0.05 , beta error level at 0.20 , effect size at 0.7 , the required sample size was determined as 26 for each group (By considering the potential data loss $10 \%$ ), we averaged the total sample size as 60 (30 patients for each group).

The data were evaluated with IBM SPSS Statistics 25.0 (IBM Corp., Armonk, New York, USA) statistical package software. In the complete data, the number of units, denoted by $(n)$, percentage, denoted by (\%), mean \pm standard deviation, denoted by (mean $\pm \mathrm{sd}$ ), median, denoted by $(\mathrm{M})$ and quartile values, denoted by $\left(Q_{1}, Q_{3}\right)$ were used as descriptive statistics. The Shapiro-Wilk Normality Test was used for the normality distribution of the numerical variables and Q1-Q3 graphics were used for evaluation. The Independent Samples t-Test was used for the comparisons between saline and air group for normally distributed variables, and the Mann-Whitney U test was used for non-normally distributed variables.

Since, there were missing observations in repetitive measurements, the comparison of the groups over time was made with mixed effect models. The estimation of missing observations was made according to the restricted maximum likelihood method. The Bonferroni test was used for multiple comparisons. The descriptive statistics were given as the predictive values of the mean and standard error (mean \pm sd ) in the comparisons with missing observations in the findings. Spearman Correlation Analysis was used to examine the relationships between measurements. $\mathrm{p}<0.05$ was considered statistically significant.

\section{RESULTS}

Demographic and clinical characteristic data are shown in Table I. The cuff pressures of patients in Group S in TP and in supine position maximum cuff pressure values were significantly lower than in Group A, and peak airway pressure values in the supine position were found to be significantly high $(\mathrm{p}<0.05)$.

There was no significant difference between the groups during follow-up periods in terms of heart rate, mean arterial pressure, $\mathrm{EtCO}_{2}$, internal PEEP, and IAP values ( $\left.\mathrm{p}>0.05\right)$.
Cuff pressure values at $10^{\text {th }}, 20^{\text {th }}, 30^{\text {th }}, 40^{\text {th }}$ and $50^{\text {th }}$ minutes were found to be significantly lower in Group $S$ than in Group A ( $p$ $<0.05$ ) (Table II).

When the airway pressure change of the groups was compared, the airway pressure values were found to be significantly higher in Group $S$ than in Group A regarding the measurements immediately after intubation and at the $10^{\text {th }}$ minute $(\mathrm{p}<0.001$, for all) (Table III).

Group S had significantly lower NRS values than Group A at the postoperative $2^{\text {nd }}$ and $24^{\text {th }}$ hours, when groups were compared for sore throat without swallowing and swallowing $(\mathrm{p}<0.001$, for all) (Table IV).

Total tramadol consumption of the groups in the postoperative 24-hour period was significantly lower in Group S compared to in Group A ( $\mathrm{p}=0.002)$ (Figure 1).

A moderate correlation was found between the duration of pneumoperitoneum and TP airway pressure $(r=0.596, p$ $<0.001$ ), and a weak positive correlation was found between supine peak airway pressure and TP cuff pressure change for all patient groups $(\mathrm{r}=0.281, \mathrm{p}=0.015 ; \mathrm{r}=0.257, \mathrm{p}=0.027$, respectively) (Table V).

Table I. Demographic and clinical characteristic.

\begin{tabular}{|c|c|c|c|}
\hline & $\begin{array}{l}\text { Group S } \\
(\mathrm{n}=30)\end{array}$ & $\begin{array}{c}\text { Group A } \\
(\mathrm{n}=30)\end{array}$ & p \\
\hline \multicolumn{4}{|l|}{ Demographic data } \\
\hline Age (year) & $39.9 \pm 13.8$ & $37.9 \pm 12.5$ & 0.517 \\
\hline BMI (kg.m-2) & $27.1 \pm 6.7$ & & 0.955 \\
\hline ASA (I/II/III) & $14 / 12 / 4$ & $13 / 14 / 3$ & 0.511 \\
\hline \multicolumn{4}{|l|}{ Intraoperative data } \\
\hline Anesthesia time (min) & $80(64-125)$ & $85(65-125)$ & 0.905 \\
\hline Operation time (min) & $75(60-118)$ & $80(60-120)$ & 0.641 \\
\hline Pneumoperitoneum time (min) & $45(30-81.3)$ & $45(24.5-91.3)$ & 0.854 \\
\hline $\begin{array}{l}\text { Trendelenburg position time } \\
\text { (min) }\end{array}$ & $50(35-87.5)$ & $47,5(25-95)$ & 0.516 \\
\hline Supine position time (min) & $30(20.5-40)$ & $35(25-40)$ & 0.192 \\
\hline \multicolumn{4}{|l|}{ Intraoperative pressures } \\
\hline $\begin{array}{l}\text { Supine peak airway pressure } \\
\left(\mathrm{cm} \mathrm{H}_{2} \mathrm{O}\right)\end{array}$ & $24,5(18.3-27)$ & $18,5(16-21,3)$ & 0,001 \\
\hline Supine cuff pressure $\left(\mathrm{cm} \mathrm{H}_{2} \mathrm{O}\right)$ & $26,5(25-28)$ & $28(26-30)$ & 0,040 \\
\hline $\begin{array}{l}\text { Trendelenburg position peak } \\
\text { airway pressure }\left(\mathrm{cm} \mathrm{H}_{2} \mathrm{O}\right)\end{array}$ & $27(22-29.8)$ & $27(21-32)$ & 0,991 \\
\hline $\begin{array}{l}\text { Trendelenburg position cuff } \\
\text { pressure }\left(\mathrm{cm} \mathrm{H}_{2} \mathrm{O}\right)\end{array}$ & $28(28-30)$ & $32(30-35)$ & $<0,001$ \\
\hline $\begin{array}{l}\text { Maximum cuff pressure } \\
\left(\mathrm{cmH}_{2} \mathrm{O}\right)\end{array}$ & $28(28-30)$ & $32(30-35)$ & $<0,001$ \\
\hline
\end{tabular}

Group S: saline, Group A: air, ASA: American Society of Anesthesiologists Classification, BMI: body mass index. Data presented as mean \pm SD or median. 
Table II. Changes in endotracheal tube cuff pressure during surgery in groups

\begin{tabular}{|c|c|c|c|c|c|c|c|c|c|c|c|c|c|}
\hline Group & $\begin{array}{l}\text { Immediately } \\
\text { after } \\
\text { intubation }\end{array}$ & & 20 min after & $\begin{array}{l}30 \mathrm{~min} \\
\text { after } \\
\text { atubation }\end{array}$ & $\begin{array}{l}40 \mathrm{~min} \\
\text { after }\end{array}$ & $\begin{array}{l}50 \mathrm{~min} \\
\text { after }\end{array}$ & $\begin{array}{l}60 \mathrm{~min} \\
\text { after }\end{array}$ & $\begin{array}{l}70 \mathrm{~min} \\
\text { after } \\
\text { ntubation }\end{array}$ & 80 min after & $\begin{array}{l}90 \mathrm{~min} \\
\text { after }\end{array}$ & $\begin{array}{c}100 \mathrm{~min} \\
\text { after } \\
\text { intubation }\end{array}$ & $\begin{array}{c}110 \mathrm{~min} \\
\text { after } \\
\text { intubation }\end{array}$ & $\begin{array}{l}120 \text { min } \\
\text { after } \\
\text { intubation }\end{array}$ \\
\hline Group S & $25.0 \pm 00$ & $25.5 \pm 0.2$ & $26.7 \pm 0.5$ & $27.4 \pm 0.7$ & $27.9 \pm 0.6$ & $28.6 \pm 0.6$ & $28.5 \pm 0.6$ & $28.4 \pm 0.7$ & $28.5 \pm 0.7$ & $28.1 \pm 0.8$ & $26.7 \pm 0.9$ & $27.5 \pm 0.9$ & $27.4 \pm 0.9$ \\
\hline Group A & $25.0 \pm 00$ & $26.8 \pm 0.2$ & $30.5 \pm 0.5$ & $31.1 \pm 0.7$ & $31.2 \pm 0.6$ & $30.3 \pm 0.6$ & $30.1 \pm 0.6$ & $29.6 \pm 0.6$ & $28.6 \pm 0.6$ & $28.2 \pm 0.8$ & $27.2 \pm 0.9$ & $27.1 \pm 0.8$ & $26.6 \pm 0.9$ \\
\hline$P$ value & - & $<0.001$ & $<0.001$ & $<0.001$ & $<0.001$ & 0.046 & 0.081 & 0.189 & 0.864 & 0.898 & 0.881 & 0.782 & 0.589 \\
\hline
\end{tabular}

Group S: saline, Grup A: air. Data presented as mean $\pm S D, n=30$ in groups, cm H2O)

Table III. Changes in peak airway pressure during surgery in groups

\begin{tabular}{lcccccccccccccc} 
Group & $\begin{array}{c}\text { Immediately } \\
\text { after } \\
\text { intubation }\end{array}$ & $\begin{array}{c}10 \mathrm{~min} \\
\text { after } \\
\text { intubation intubation }\end{array}$ & $\begin{array}{c}20 \mathrm{~min} \\
\text { after }\end{array}$ & $\begin{array}{c}30 \mathrm{~min} \\
\text { after }\end{array}$ & $\begin{array}{c}40 \mathrm{~min} \\
\text { after }\end{array}$ & $\begin{array}{c}50 \mathrm{~min} \\
\text { after }\end{array}$ & $\begin{array}{c}60 \mathrm{~min} \\
\text { after }\end{array}$ & $\begin{array}{c}70 \mathrm{~min} \\
\text { after }\end{array}$ & $\begin{array}{c}80 \mathrm{~min} \\
\text { after }\end{array}$ & $\begin{array}{c}90 \mathrm{~min} \\
\text { after }\end{array}$ & $\begin{array}{c}100 \mathrm{~min} \\
\text { after }\end{array}$ & $\begin{array}{c}110 \mathrm{~min} \\
\text { after }\end{array}$ & $\begin{array}{c}120 \mathrm{~min} \text { after } \\
\text { intubation }\end{array}$ \\
Group S & $22.2 \pm 09$ & $23.5 \pm 1.0$ & $24.8 \pm 1.2$ & $24.5 \pm 1.1$ & $23.9 \pm 1.1$ & $23.8 \pm 1.1$ & $22.4 \pm 1.3$ & $21.9 \pm 1.2$ & $21.1 \pm 1.4$ & $19.9 \pm 1.8$ & $19.8 \pm 2.1$ & $24.2 \pm 1.6$ & $33.8 \pm 3.4$ \\
Group A & $16.4 \pm 09$ & $17.9 \pm 0.9$ & $22.3 \pm 1.1$ & $24.7 \pm 1.0$ & $24.2 \pm 1.1$ & $23.2 \pm 1.1$ & $22.0 \pm 1.2$ & $22.0 \pm 1.2$ & $20.4 \pm 1.4$ & $19.5 \pm 1.7$ & $17.9 \pm 2.0$ & $22.4 \pm 1.5$ & $33.7 \pm 3.2$ \\
P value & $<0.001$ & $<0.001$ & 0.133 & 0.916 & 0.857 & 0.682 & 0.823 & 0.953 & 0.730 & 0.875 & 0.525 & 0.433 & 0.996 \\
\hline
\end{tabular}

Group S: saline, Grup A: air. Data presented as mean $\pm S D, n=30$ in groups, $\mathrm{cm}_{2} \mathrm{O}$ ).

Table IV. Sore throat scores with and without swallowing in the postoperative period

\begin{tabular}{lcccc} 
& $\begin{array}{r}\text { Group S } \\
(\mathbf{n = 3 0 )}\end{array}$ & $\begin{array}{r}\text { Group A } \\
(\mathbf{n}=\mathbf{3 0})\end{array}$ & p \\
\hline $\begin{array}{l}\text { Sore throat with swallowing at the 2nd } \\
\text { hours postoperatively }\end{array}$ & $0(0-1)$ & $3(1-4)$ & $<\mathbf{0 . 0 0 1}$ \\
$\begin{array}{l}\text { Sore throat without swallowing at the 2nd } \\
\text { hours postoperatively }\end{array}$ & $0(0-0)$ & $2(0-3)$ & $<\mathbf{0 . 0 0 1}$ \\
$\begin{array}{l}\text { Sore throat with swallowing at the 24nd } \\
\text { hours postoperatively }\end{array}$ & $0(0-0)$ & $2(0-3)$ & $<\mathbf{0 . 0 0 1}$ \\
$\begin{array}{l}\text { Sore throat without swallowing at the } \\
\text { 24nd hours postoperatively }\end{array}$ & $0(0-0)$ & $1(0-2)$ & $<\mathbf{0 . 0 0 1}$ \\
\hline
\end{tabular}

Group S: saline, Group A: air

Table V. Correlations between pneumoperitoneum time and peak airwaycuff pressures change

\begin{tabular}{lc}
\hline & $\begin{array}{c}\text { Pneumoperitoneum time } \\
\text { All Groups } \\
(\mathrm{n}=60)\end{array}$ \\
\hline $\begin{array}{ll}\text { Trendelenburg position peak airway pressure change } \\
\text { rho }\end{array}$ & 0.596 \\
$\mathrm{p}$ & $<0.001$ \\
\hline Supine position peak airway pressure change & \\
rho & 0.281 \\
$\mathrm{p}$ & 0.015 \\
\hline Trendelenburg cuff pressure change & \\
rho & 0.257 \\
$\mathrm{p}$ & 0.027 \\
Supine position cuff pressure change & \\
rho & 0.126 \\
$\mathrm{p}$ & 0.287 \\
\hline
\end{tabular}

rho: correlation coefficient

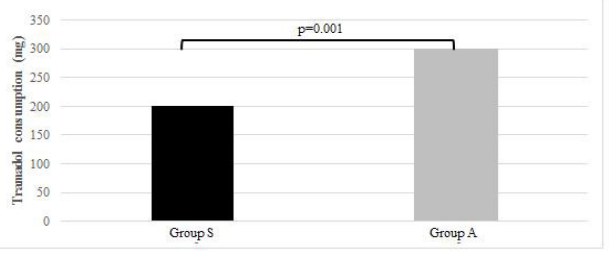

Figure 1. Total tramadol consumption of the groups in the postoperative 24 hour period $(m g)$.

Group S, saline; Group A, air.

\section{DISCUSSION}

In our study, lower cuff pressures, less sore throat, and fewer analgesic requirements were reported in the patients whose ETT cuffs were insufflated with saline compared to the air-insufflated group in the operations performed with the gynecological laparoscopic method in the TP.

Endotracheal intubation is a frequently used method to ensure airway safety. However, due to the increase in cuff pressures of the cuffed ETTs, frequently used during EI, laryngotracheal morbidity can occur due to damage to the tracheal mucosa which contacts with the cuff [21]. Increased cuff pressure can cause tracheal complications in short-term surgeries as well as long-term surgeries [22]. In vivo studies have shown that tracheal capillary perfusion pressure ranges from 30 to 44 $\mathrm{mmHg}$ [14]. Thus, as a general approach, the intraoperative cuff pressure is recommended to be $20 \mathrm{~cm} \mathrm{H}_{2} \mathrm{O}$ [23]. High cuff pressures in the intraoperative period may cause sore throat and hoarseness during the postoperative period [24]. In our study Group S had significantly lower NRS values than Group A at the postoperative $2^{\text {nd }}$ and $24^{\text {th }}$ hours. 
Laparoscopic surgery is common, and it has many advantages [25]. In laparoscopic surgeries, $\mathrm{CO}_{2}$ is commonly used to provide intra-abdominal distention to improve the surgical field of view [26]. After the TP with pneumoperitoneum (PP), the diaphragm increases, even more, lung expansion is restricted and lung compliance decreases due to the increase in airway pressures [25]. The pressure applied to the trachea wall also increases due to the increase in cuff pressures caused by the increase in airway pressures depending on $\mathrm{CO}_{2} \mathrm{PP}$. Due to this pressure increase, it can cause ischemic damage and tracheal necrosis as a result of the disruption of perfusion in the tracheal mucosa [22]. As a result of all these, sore throat and hoarseness are common during the postoperative period.

In a study by Yildırım $\mathrm{Z}$ et al., it was reported that the effect of PP on cuff pressure in patients undergoing laparoscopic cholecystectomy and open abdominal surgery, the cuff pressures were found to be higher in the laparoscopic group during all follow-up periods. Besides, the cuff pressure was found to exceed $30 \mathrm{~cm} \mathrm{H}_{2} \mathrm{O}$ after the first $5^{\text {th }}$ minute of PP. In the clinical image of this pressure increase, sore throat was found to be higher in the laparoscopic group at the $12^{\text {th }}$ hour after the surgery [26]. While laparoscopic cholecystectomy operations are often performed in the reverse TP position, we performed our gynecological operations in the TP position.

The position of the patient is as important as the insufflation of the abdomen to provide a good surgical view in the operations performed with the laparoscopic method. This can increase the risk of airway complications in the postoperative period [27]. A frequently used position in gynecological laparoscopic operations, TP was found to increase cuff pressure significantly and the frequency of postoperative sore throat compared to laparotomy patients [15]. In a study conducted by Geng G et al., cuff and airway pressures and postoperative sore throat of patients undergoing open and laparoscopic gynecological surgery were compared. A significant increase was observed in airway and EI cuff pressures in the TP after PP in the laparoscopic group compared to the open surgery group. Besides, sore throat at the $2^{\text {nd }}$ and $24^{\text {th }}$ hours after surgery was found to be significantly higher in the laparoscopic group compared to the open surgery group [15].

In a study of $\mathrm{Wu} \mathrm{CY}$ et al., the effects of $\mathrm{PP}$ and surgical position on the cuff and airway pressures in laparoscopic surgery were investigated, no significant change in the cuff and airway pressures were observed during 15 minutes before PP, while a significant increase in the mean airway and cuff pressures was detected in patients in the TP. Although, there was a strong correlation between airway pressure change and cuff pressures caused by abdominal insufflation, there was no correlation between position [16].

Kwon $\mathrm{Y}$ et al. investigated the relationship between ETT cuff pressure change and body mass index (BMI), pneumoperitoneum period, and cuff pressure in patients undergoing laparoscopic cholecystectomy. $\mathrm{N}_{2} \mathrm{O}$ was used for analgesic purposes during surgery. There was no difference between airway pressures and cuff pressures throughout the operation between groups with different BMIs. In the same study, there was a weak positive correlation between pneumoperitoneum duration and cuff pressure change. The change in cuff pressure was not affected by BMI, but pneumoperitoneum duration caused a change in cuff pressure [28]. In our study, there was no significant difference in BMI between groups. In addition, we found a weak correlation between pneumoperitoneum duration and cuff pressure change in the TP.

In the study conducted by Rosero EB et al., in patients with $\mathrm{BMI} \geq 30 \mathrm{~kg} / \mathrm{m}^{2}$, who underwent laparoscopic gynecological surgery without using nitrous oxide, the mean cuff pressure, and peak airway pressures were found to be significantly higher in PP period than the period from intubation to insufflation of the abdomen. Besides, the increase in peak airway pressure and cuff pressure was reported to be related to each other, and every $1 \mathrm{~cm} \mathrm{H_{2 }} \mathrm{O}$ increase in peak airway pressure was found to cause a $0.25 \mathrm{~cm} \mathrm{H}_{2} \mathrm{O}$ increase in EI cuff pressure [9]. In our study, we investigated the relationship between pneumoperitoneum periods and peak airway pressures in the TP. A moderate correlation was reported between PP time and peak airway pressure change in the TP. Therefore, we believe that increase in peak airway pressures in the TP would cause an increase in cuff pressure.

The frequency of postoperative sore throat induced by EI ranges from 60 to $90 \%$ [29]. Depending on the swelling of the cuff and damage to the pharyngeal mucosa and recurrent laryngeal nerve, it can lead to many complications such as hoarseness, aphonia, stridor and respiratory distress. Postoperative sore throat is also affected from the factors such as age, gender, intubation conditions the diameter of the ETT, the shape of the cuff, the movement of the EI in the trachea, the medical gases used and the increased cuff pressure [30].

In the literature, the fluid mechanics was used to explain the basis of the studies carried out with saline-insufflated ETT cuff to prevent postoperative sore throat after EI. According to the Pascal principle, given the mechanics of fluids, the pressure, applied externally to a system, is transmitted equally by the liquid to all points of the liquid and every point of the inner surfaces of the container regardless of the volume of the container [31]. In accordance with the same principle, during positive pressure ventilation, the trachea and the ETT cuff are considered as part of the same closed pneumatic system [9]. In the light of this information, we determined the hypothesis of our study as the insufflation of the cuffs of the EI tubes with saline to prevent the increase of EI cuff pressure in gynecological laparoscopic operations performed in TP and to prevent postoperative sore throat.

Ahmad NL et al., found that the cuff pressures were lower in the saline-insufflated ETT cuff group than the air-insufflated group in patients undergoing elective abdominal and limb surgery under general anesthesia with $\mathrm{N}_{2} \mathrm{O}$ [32]. In our study, cuff pressures were reported to be lower in the group whose cuffs were insufflated with saline to prevent postoperative complications due to possible high cuff pressures in the TP, while remifentanil was used instead of nitrous oxide when maintaining the patients' heads and necks in the neutral position. As a result, less sore 
throat was observed in the postoperative period due to low cuff pressures in the saline-insufflated group.

In a study by Besir A et al., the ETT cuffs were insufflated with saline and air in patients under low flow general anesthesia using $\mathrm{N}_{2} \mathrm{O}$. The ETT cuff pressures were found to be lower in the saline-insufflated group with the prevention of the diffusion of $\mathrm{N}_{2} \mathrm{O}$ into the cuff, and the sore throat was significantly lower in the saline-insufflated group during the postoperative period [33].

In a study by Shroff PP et al., in which the ETT cuffs were insufflated with air, saline, and $2 \%$ lignocaine, cuff pressure, postoperative sore throat, and hoarseness in the saline group were the same as the group insufflated with $2 \%$ lignocaine and were significantly lower than air-insufflated group [34].

In the laparoscopic gynecological operations performed in the TP, insufflation of ETT cuffs in the prevention of postoperative sore throat due to the increase in cuff pressures are not common in the literature. In our study, we concluded that sore throat can be prevented by preventing the increase of intraoperative cuff pressure with the insufflation of ETT cuff with saline.

\section{Limitations}

There are some limitations of our study. First, we could not directly evaluate the tracheal mucosal damage, which could reveal the symptoms of hoarseness and sore throat that may occur in the trachea after EI and develop in the postoperative period. Second, the patients were followed up for 24 hours in the postoperative period. Although, the frequency and severity of sore throat tend to decrease in the postoperative 24-hour period, there is a need for longer periods of follow-up for the evaluation of postoperative sore throat and hoarseness in the long term. Third, we used the ETTs of a single type from the same manufacturer. Therefore, our findings may not apply to different types of ETTs produced by different manufacturers. Fourth, although, nitrous oxide was not used as an analgesic in the maintenance of anesthesia in our study, we did not measure the concentrations of other medical gases (e.g. CO2 or O2) that would cause pressure changes in the ETT cuffs and therefore we could not evaluate their effects on ETT cuff pressure changes. Finally, anatomical structures such as the upper part and inner diameter of the trachea differ according to the geographical regions. Since, our study is a single-center study, the results are limited to a specific region. There is a need to carry out further multi-center studies.

\section{Conclusion}

We believe that the method of the insufflation of the ETT cuff with saline, an easily applicable method, can reduce the postoperative sore throat that occurs due to the increase in ETT cuff pressure and the need for analgesic consumption that occurs accordingly in the TP in gynecological laparoscopic surgery.

\section{Compliance with Ethical Standards}

Ethical Approval: The study protocol was approved by the Institutional Ethics Committee of Karadeniz Technical
University, School of Medicine (approval number: 09.2013. 0262). All patients provided written informed consent.

Financial Disclosure: The authors declared that this study has received no financial support.

Conflict of Interest: The authors have no conflicts of interest to declare.

Authors' Contributions: Literature search: SS and AB, Study design: SS and AB, Legislative applications: $S S$ and $A B$, Data collection: SS, AA and ET, Supervision and quality control: SS, AA and ET, Statistical advice: SS and AB, Statistical data analysis:SS, AB,SS and AA, Data interpretation: SS, SS, ET and $A B$, Drafting the manuscript: SS, AB, ET and SS. All authors approved the final version of the article.

\section{REFERENCES}

[1] Morgan GE, Mikhail MS, Murray MJ, editors. Clinical Anesthesiology 5th ed.International Edition: New York: Lange Medical Books, 2015:309-41.

[2] Atlas GM. A mathematical model of differential tracheal tube cuff pressure: effects of diffusion and temperature. J Clin Monit Comput 2005;19:415-25. doi: 10.1007/s10877.005.1626-5.

[3] Girling KJ, Bedforth NM, Spendlove JL, Mahajan RP. Assessing neuromuscular block at the larynx: the effect of change in resting cuff pressure and a comparison with video imaging in anesthetized humans. Anesth Analg 1999;88:42631. doi: 10.1097/00000.539.199902000-00038.

[4] Godoy AC, Vieira RJ, Capitani EM. Endotracheal tube cuff pressure alteration after changes in position in patients under mechanical ventilation. J Bras Pneumol 2008;34:294-97. doi: 10.1590/s1806.371.3200800.050.0008.

[5] Hameed AA, Mohamed H, Al-Mansoori M. Acquired tracheoesophageal fistula due to high intracuff pressure. Ann Thorac Med 2008;3:23-5. doi: 10.4103/1817-1737.37950.

[6] Harris R, Joseph A. Acute tracheal rupture related to endotracheal intubation: case report. J Emerg Med 2000;18:359. doi: 10.1016/s0736-4679(99)00159-6.

[7] Pookamala S, Thakar A, Puri K, Singh P, Kumar R, Sharma SC. Acquired subglottic stenosis: aetiological profile and treatment results. J Laryngol Otol 2014;128:641-8. doi: 10.1017/S002.221.5114000966.

[8] Touat L, Fournier C, Ramon P, Salleron J, Durocher A, Nseir $\mathrm{S}$. Intubation-related tracheal ischemic lesions: incidence, risk factors, and outcome. Intensive Care Med 2013;39:575-82. doi: 10.1007/s00134.012.2750-6.

[9] Rosero EB, Ozayar E, Eslava-Schmalbach J, Minhajuddin A, Joshi GP. Effects of increasing airway pressures on the pressure of the endotracheal tube cuff during pelvic laparoscopic surgery. Anesth Analg 2018;127:120-5. doi: 10.1213/ ANE.000.000.0000002657.

[10] American Thoracic Society, Infectious Diseases Society of America. Guidelines for the management of adults with hospital - acquired, ventilator-associated, and healthcareassociated pneumonia. Am J Respir Crit Care Med 2005;171:388-416. doi: 10.1164/rccm.200405-644ST. 
[11] Bernhard WN, Yost L, Joynes D, Cothalis S, Turndorf H. Intracuff pressures in endotracheal and tracheostomy tubes. Related cuff physical characteristics. Chest 1985;87:720-5. doi: 10.1378/chest.87.6.720.

[12] Diaz E, Rodríguez AH, Rello J. Ventilator-associated pneumonia: issues related to the artificial airway. Respir Care 2005;50:900-6.

[13] Nordin U. The trachea and cuff-induced tracheal injury. An experimental study on causative factors and prevention. Acta Otolaryngol Suppl 1977;345:1-71.

[14] Seegobin RD, van Hasselt GL. Endotracheal cuff pressure and tracheal mucosal blood flow: endoscopic study of effects of four large volume cuffs. Br Med J (Clin Res Ed). 1984;288:9658. doi: 10.1136/bmj.288.6422.965.

[15] Geng G, Hu J, Huang S. The effect of endotracheal tube cuff pressure change during gynecological laparoscopic surgery on postoperative sore throat: a control study. Journal of Clin Monit Comput 2015;29:141-4. doi: 10.1007/s10877.014.95782.

[16] Wu CY, Yeh YC, Wang MC, Lai CH, Fan SZ. Changes in endotracheal tube cuff pressure during laparoscopic surgery in head-up or head-down position. BMC Anesthesiology 2014 31;14:75. eCollection 2014. doi: 10.1186/1471-2253-14-75.

[17] Farhang, B, Grondin, L. The effect of zinc lozenge on postoperative sore throat: a prospective randomized, doubleblinded, placebo-controlled study. Anesthesia \& Analgesia 2018; 126:78-83. doi: 10.1213/ANE.000.000.0000002494.

[18] Kuriyama, A, Maeda, H, Sun, R, Aga, M. Topical application of corticosteroids to tracheal tubes to prevent postoperative sore throat in adults undergoing tracheal intubation: a systematic review and meta-analysis. Anaesthesia 2018;73:1546-56. doi: 10.1111/anae.14273.

[19] Sanaie S, Rahmani F, Chokhachian S, et al. Comparison of tracheal tube cuf pressure with two technique: fxed volume and minimal leak test techniques. J Cardiovasc Thorac Res. 2019;11:48-52. doi: 10.15171/jcvtr.2019.08.

[20] Aldrete JA. Post-anesthesia recovery score revisited. J Clin Anesth 1995;7:89-91. doi: 10.1016/0952-8180(94)00001-K

[21] Mol DA, De Villers Gdu T, Claassen AJ, Joubert G. Use and care of an endotracheal/tracheostomy tube cuff-are intensive care unit staff adequately informed? S Afr J Surg 2004;42:14-6.

[22] Liu J, Zhang X, Gong W et al. Correlations between controlled endotracheal tube cuff pressure and postprocedural complications: A multicenter study. Anesth Analg 2010;111:1133-7. doi: 10.1213/ANE.0b013e3181f2ecc7.

[23] Rello, J, Sonora, R, Jubert, P, Artigas, A, Rué, M, Vallés, J. Pneumonia in intubated patients: role of respiratory airway care. Am J Respir Crit Care Med 1996;154:111-5. doi: 10.1164/ ajrccm.154.1.8680665.
[24] Jaensson M, Gupta A, Nilsson UG. Gender differences in risk factors for airway symptoms following tracheal intubation. Acta Anaesthesiol Scand 2012;56:1306-13. doi: 10.1111/j.13996576.2012.02771.x.

[25] Cakmakkaya, O. S, Kaya, G, Altintas, F, Hayirlioglu, M, Ekici, B. Restoration of pulmonary compliance after laparoscopic surgery using a simple alveolar recruitment maneuver. J Clin Anesth 2009;21:422-6. doi: 10.1016/j.jclinane.2009.08.001.

[26] Yildirim Z B, Uzunkoy A, Cigdem A, Ganidagli S, Ozgonul A. Changes in cuff pressure of endotracheal tube during laparoscopic and open abdominal surgery. Surg Endosc 2012; 26:398-401. doi: 10.1007/s00464.011.1886-8.

[27] Gerges FJ, Kanazi GE, Jabbour-Khoury SI. Anesthesia for laparoscopy: a review. J Clin Anesth 2006;18:67-78. doi: 10.1016/j.jclinane.2005.01.013.

[28] Kwon Y, Jang J S, Hwang S M, et al. The change of endotracheal tube cuff pressure during laparoscopic surgery. Open Medicine 2019;14:431-6. doi: 10.1515/med-2019-0046.

[29] Estebe JP, Delahaye S, Le Corre P, et al. Alkalinization of intra-cuff lidocaine and use of gel lubrication protect against tracheal tube-induced emergence phenomena. Br J Anaesth 2004;92:361-6. doi: 10.1093/bja/aeh078.

[30] Chang J E, Kim H, Han S H, Lee J M, Ji S, Hwang J Y. Effect of endotracheal tube cuff shape on postoperative sore throat after endotracheal intubation. Anesthesia \& Analgesia 2017; 125:1240-5. doi: 10.1213/ANE.000.000.0000001933.

[31] Canbay O, Celebi N, Sahin A, Celiker V, Ozgen S, Aypar U. Ketamine gargle for attenuating postoperative sore throat. Br J Anaesth 2008;100:490-3. doi: 10.1093/bja/aen023.

[32] Halliday D, Resnick R, Walker J. Fundamentals of physics. New York, NY, Wiley, 2001.

[33] Ahmad N L, Norsidah A M. Change in endotracheal tube cuff pressure during nitrous oxide anaesthesia: A comparison between air and distilled water cuff inflation Anaesthesia and Intensive Care 2001;29:510-4. doi: 10.1177/0310057X010.290.0511.

[34] Beşir A, Erdoğan G. Comparison between cuff pressures of endotracheal tubes inflated with saline or air in low-flow anesthesia. Clin Exp Health Sci 2018; 8:112-7. doi:10.5152/ clinexphealthsci.2017.537.

[35] Shroff PP, Patil V. Efficacy of cuff inflation media to prevent postintubation-related emergence phenomenon: air, saline and alkalinized lignocaine. Eur J Anaesthesiol 2009;26:45862. doi: 10.1097/eja.0b013e32832403fa.

[36] Kumar S P, Ravikumar A. Biometric study of the internal dimensions of subglottis and upper trachea in adult Indian population. Indian Journal of Otolaryngol Head Neck Surg 2014;66:261-6. doi: 10.1007/s12070.012.0477-x. 